Original Research Paper

\title{
Jenis-Jenis Tumbuhan Paku di Pulau Rangsang, Kepulauan Meranti, Riau dan Karakteristik Morfologi-Palinologi
}

\author{
Nery Sofiyanti $^{1^{*}}$, Afni Atika Marpaung ${ }^{2}$, Rissan Suriatno $^{3}$, Syafroni Pranata $^{4}$ \\ 1,3Jurusan Biologi, Fakultas MIPA, Universitas Riau, Pekanbaru, Riau, Indonesia \\ ${ }^{2}$ Program Pascasarjana Biologi, Unversitas Gadjahmada, Yogyakarta, Indonesia \\ ${ }^{4}$ Divisi Ekologi, Generasi Biologi Indonesia (Genbinesia) Foundation, Gresik, Jawa Timur
}

\section{Riwayat artikel}

Received : 24 Februari 2020

Revised : 04 Maret 2020

Accepted : 16 Maret 2020

Published : 23 Maret 2020

*Corresponding Author:

Nery Sofiyanti,

Jurusan biologi FMIPA

Universitas Riau, Pekanbaru,

Riau, Indonesia

Email:

nery.sofiyanti@lecturer.unri.ac.id

\begin{abstract}
Abstrak: Pulau Rangsang meupakan salah satu pulau utama di Kabupaten Kepulauan Meranti, Provinsi Riau yang mempunyai keunikan habitat bagi berbagai jenis flora termasuk golongan tumbuhan paku. Namun data mengenai keanekaragaman flora paku di pulau ini belum pernah dilaporkan sebelumnya. Tujuan dari penelitian ini adalah untuk menginventarisasi jenisjenis tumbuhan paku di Pulau Rangsang serta mengkarakterisasi morfologi dan sporanya. Pengambilan sampel dilakukan dengan metode eksplorasi sedangkan pembuatan preparat spora dengan metode asetolisis dan tanpa asetolisis. Sebanyak 23 jenis tumbuhan paku telah di identifikasi di lokasi kajian, yang tergolong dalam 8 Famili, 3 Ordo dan 1 Divisi Polypodiophyta. Tipe dasar spora yang ditemukan adalah monolete, dan trilete, dengan laesura monosulkat dan trikomonosulkat. Tipe spora berdasarkan ukuran yang ditemukan adalah ukuran spora medium dan spora besar.
\end{abstract}

Kata Kunci: Morfologi, kawasan pesisir, paku laut, palinologi, spora

Abstract: Rangsang Island is one of main island of Kepulauan Meranti, Riau Province that poses a uniqe habitat for flora including ferns. However, the data of fern diversity from this island had not been reported. The aim of this study were to inventory ferns from Rangsang Island and to characterize their morphologies and spore characteristics. Sample collection was carried out using exploration method, while spore preparation used acetolysis and non acetolysis method. A total of 23 fern species are identified from the study sites. They belong to 8 families, 3 orders from Division Polypodiophyta. Basic spore type observed in this study are monolete and trilete, with monosulcate and trichomonosulcate laesura. Spore types based on its size found in this study are medium and large spore.

Keywords: coastal area, morphology, palynology, sea fern, spore

\section{Pendahuluan}

Tumbuhan paku merupakan golongan tumbuhan yang menghasilkan spora namun sudah mempunyai berkas pengangkut, sehingga termasuk dalam tumbuhan vaskular. Jumlah jenis tumbuhan paku cukup tinggi yaitu sekitar 10.000 (Christenhusz et al. 2011) sampai 11.000 jenis (Jeffrey 2004) yang tersebar di berbagi tipe habitat seperti terestrial, aquatik dan epifit. Kajian mengenai tumbuhan paku di Sumatera telah banyak dilaporkan sebelumnya. Sedangkan di Provinsi Riau, kajian mengenai tumbuhan paku telah dilakukan oleh Sofiyanti (2013) yang mengidentifikasi 13 jenis paku epifit di kelapa sawit Pekanbaru. Inventarisasi tumbuhan di kawasan Taman Hutan Raya Sultan Syarif Qasim juga telah dilaporkan oleh Sofiyanti et al. (2015) yang mengidentifikasi 43 jenis paku. Sedangkan Wulandari et al. (2016) dan Yusna et al. (2016) telah mengkaji keanekaragaman jenis paku di Hutan CPI Rumbai berdasarkan fitomikia

Kajian keanekaragaman tumbuhan di Provinsi Riau lebih banyak dilaporkan dari kawasan Riau daratan dibandingkan dengan kawasan pesisir yang terdiri dari pulau-pulau. Padahal pulau - pulau di ini mempunyai keunikan habitat bagi berbagai jenis flora termasuk golongan tumbuhan paku. Pulau Rangsang, Kepulauan 
Meranti merupakan salah satu pulau utama di kawasan pesisir Provinsi Riau. Sebagian besar wilayah di pulau ini merupakan daerah gambut (Hakim et al. 2016) yang mempunyai peranan ekologis yang sangat penting. Namun data mengenai keanekaragaman flora paku di Pulau Rangsang belum pernah dilaporkan sebelumnya, sehingga perlu dilakukan kajian mengenai keanekaragaman paku di pulau ini agar dapat dijadikan sebagai data awal dalam pengelolan kawasan gambut. Dalam mengkaji keanekaragaman tumbuhan, kajian palinologi memegang peranan penting karena mendukung status taksonomi suatu jenis tumbuhan, termasuk tumbuhan paku. Kajian ini berkaitan dengan karakteristik polen (tumbuhan tingkat tinggi) atau spora (tumbuhan tingkat rendah). Kajian morfologi spora di Sumatera, khususnya Provinsi Riau masih sangat terbatas, dan baru dilaporkan oleh Marpaung (2016) mengenai morfologi spora paku Pteridaceae dari Hutan CPI Rumbai serta Sofiyanti (2019) untuk kawasan pesisir di Priovinsi Riau. Sednagkan kajian palinologi di wilayah kepualauan baru dilaporkan oleh Sofiyanti et al. (2019) dari Pulau Bengkalis, Riau.

\section{Bahan dan Metode}

\section{Pengambilan Sampel}

Eksplorasi jenis-jenis tumbuhan paku dilakukan di Pulau Rangsang, Kepulauan Meranti, Provinsi Riau. Pengambilan sampel dilakukan dengan menggunakan metode jelajah berdasarkan Namau (1992), dengan mengambil semua jenis paku yang dijumpai. Bagian tumbuhan yang diambil meliputi akar, batang dan daun terutama daun yang telah menghasilkan spora. Dokumentai dilakukan pada setiap organ semua jenis tumbuhan paku yang ditemukan. Spesimen yang diambil diberi label yang berisi catatan kode spesimen, lokasi, waktu pengambilan, habitat, titik koordinat serta karakkteristik setiap jenis. Gambar 1 menunjukan lokasi Pulau Rangsang, Kepulauan Meranti.

\section{Pembuatan herbarium}

Spesimen hasil koleksi di lapangan dibawa ke Laboratorium Botani, Jurusan Biologi FMIPA Universitas Riau untuk dibuat herbarium, dengan langkah pengepresan, pengeringan menggunakan oven, penempelan pada kertas herbarium yang dilengkapi dengan etiket tempel.

\section{Identifikasi dan Karakterisasi}

Spesimen diidentifikasi menggunakan pustaka Fern of Malaysia in Color (Piggiot 1998), Morfologi Tumbuhan paku di Taman Hutan Raya Sultan Syarif Hasyim Riau
(Sofiyanti et al. 2015) serta penelusuran secara online pada situs khusus tumbuhan paku

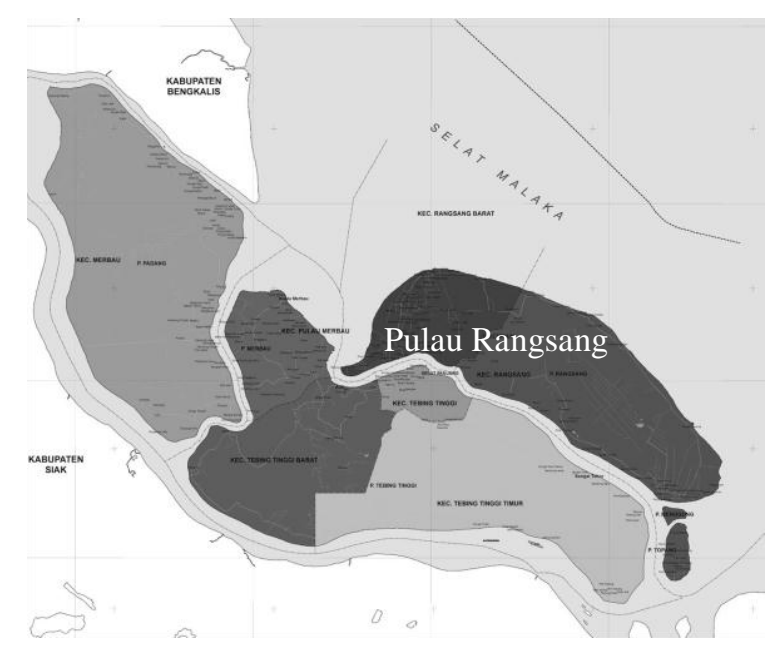

Gambar 1. Peta Pulau Rangsang, Kepulauan Meranti, Riau (Sumber: Mapdata 2020)

\section{Pembuatan preparat spora}

Pembuatan preparat awetan spora mengacu pada metode Johansen (1940), selain itu spora juga dibuat preparat tidak permanen dengan cara meneteskan gliserin pada spora. Pengamatan dan dokumentasi spora dilakukan dengan menggunakan mikroskop digital HOT dan LCD microscop Celeron. Pengukuran spora dilakukan dengan mengambil data dari 10 buah spora setiap jenisnya. Karakterisasi spora mengacu pada Erdtman (1972).

\section{Hasil dan Pembahasan}

\section{Jenis-jenis tumbuhan paku di Pulau Rangsang}

Sebanyak 23 jenis tumbuhan paku telah diidentifikasi di Pulau Rangsang, Kepulauan Meranti, Riau. Semua jenis paku yang ditemukan di lokasi kajian tergolong dalam Kelas Polypodiopsida, Divisi Polydiophyta. Divisi ini merupakan paku leptosporangiat, yaitu paku yang mempunyai sporangia yang berkembang dari sebuah sel (Smith et al. 2008. Jenis-jenis tumbuhan paku yang ditemukan pada lokasi kajian disajikan pada tabel 1.

Jenis-jenis tumbuhan paku yang ditemukan di Pulau Rangsang, Kepualaun Meranti, Provinsi Riau tergolong dalam 3 ordo yaitu Gleicheniales (1 jenis), Schizaeales (1 jenis) dan Polypodiales dengan jumlah jenis paling banyak yaitu 21 jenis yang tergolong dalam 9 famili. 
Karakteristik Morfologi jenis tumbuhan paku yang ditemukan

\section{GLECHENIALES}

\section{Glecheniaceae}

Dicranopteris linearis (Burm. f.) Underw. Terestrial. Habitat daerah terbuka atau ditepi jalan. Habitus semak. Percabangan dikotom, panjang bisa mencapai $10 \mathrm{~m}$ atau lebih. Batang Coklat kehijauan, mengkilat. Daun majemuk ganda. Sorus berada disepanjang tepi tulang anak daun, berbentuk bulat. Spesimen: RangGLNS1, RangGLNS2 Nery Sofiyanti, Rangsang 2017.

\section{SCHIZAEALES}

\section{Lygodiaceae}

Lygodium microphyllum (Cav.) R. Br. Terestrial. Habitat pada daerah terbuka, merambat pada tanaman lain. Rhizom menjalar, bisa mencapai $5 \mathrm{~m}$ atau lebih. Daun majemuk, dimorfik. Stipus $9-10 \mathrm{~cm}$. Helai anak daun hijau, membentuk segitiga, bergelombang besar, ujung membulat. Sporangia berada pada tepi daun fertil. Spesime: RangLMNS1, RangLMNS2 Nery Sofiyanti, Rangsang 2017.

Tabel 1. Jenis-jenis Tumbuhan Paku di Pulau Rangsang, Kepulauan Meranti, Riau

\begin{tabular}{|c|c|c|c|}
\hline Ordo & Famili & & Nama Jenis \\
\hline a. Glecheniales & 1. Gleicheniaceae & 1. & Dicranopteris linearis (Burm. f.) Underw. \\
\hline b. Schizaeales & 1. Lygodiaceae & 2. & Lygodium microphyllum (Cav.) R. Br. \\
\hline \multirow[t]{21}{*}{ c. Polypodiales } & 1. Aspleniaceae & 3. & Asplenium nidus L. \\
\hline & & 4. & Asplenium longissimum Blume \\
\hline & 2. Athyriaceae & 5. & Diplazium esculentum (Retz.) $\mathrm{Sw}$ \\
\hline & 3. Blechnaceae & 6. & Blechnum serrulatum Rich. \\
\hline & & 7. & Blechnum occidentale L. \\
\hline & & 8. & Stenochlaena palustris (Burm. f.) Bedd. \\
\hline & & 9. & Blecnum sp.* \\
\hline & 4. Davalliaceae & 10. & Davallia denticulata (Burm. f.) Mett. ex Kuhn \\
\hline & 5. Dennstaedtiaceae & 11. & Pteridium caudatum L. (Maxon) \\
\hline & 6. Nephrolepidaceae & 12. & Nephrolepis hirsutula (G. Forst.) C. Presl \\
\hline & 7. Onocleaceaae & 13. & Matteuccia struthiopteris (L.) Tod. \\
\hline & 8. Polypodiaceae & 14. & Drynaria sparsisora (Desv.) T. Moore \\
\hline & & 15. & Pyrosia hetrophyla L.) M.G. Price. \\
\hline & & 16. & Pyrrosia piloselloides (L.) M.G. Price. \\
\hline & & 17. & Selliguea feei Bory \\
\hline & 9. Pteridaceae & 18. & Acrostichum aureum L. \\
\hline & & 19 & Acrostichum speciosum Willd. \\
\hline & & 20. & Adiantum latifolium Lam.* \\
\hline & & 21. & Adiantum peruvianum Klotzsch \\
\hline & & 22. & Pteris vitata $\mathrm{L}$. \\
\hline & & 23. & Taenitis blechnoides (Willd.)Sw. \\
\hline
\end{tabular}

Keterangan: *saat inventarisasi tidak ditemukan individu yang menghasilkan spora

\section{POLYPODIALES}

\section{Aspleniaceae}

Asplenium nidus L. Epifit. Daun tunggal, tersusun roset basal membentuk seperti sarang burung. Tangkai daun coklat kehitaman. Helai daun bisa mencapai 1.5 m. Sori bentuk garis, tersusun di kanan dan kiri tulang daun. Spesimen: RangANNS1, Rang ANNS2 Nery Sofiyanti, Rangsang 2017.
Asplenium longisimum. Terestrial. Tumbuh di daerah ternaungi. Daun majemuk, linear, panjang bisa mencapai 1 meter. Ujung daun dewasa dapat tumbuh bulbil. Sori memanjang di kanan kiri tulang anak daun. Spesimen: RangLLNS1, RangLLMNS2 Nery Sofiyanti, Rangsang 2017.

\section{Athyriaceae}

Diplazium esculentum (Retz.) Sw. Terestrial. Daun majemuk. Ental muda hijau gelap, mengkilat, dapat 
dimakan. Spesimen: RangDENS1, RangDENS2 Nery Sofiyanti, Rangsang 2017.

\section{Blechnaceae}

Blechnum serrulatum (Retz.) Sw. Terestrial. Daun majemuk, anak daun tersusun berseling menghadap ke atas. Anak daun hijau muda. Sori berbentuk garis tebal berada disepanjang kanan kiri tulang anak daun, coklat tua. Spesimen: RangBSNS1, RangBSNS2 Nery Sofiyanti, Rangsang 2017.

Blechnum occidentale L Terestrial. Daun majemuk, anak daun tersusun berseling, hijau kemerahan saat muda dan hijau tua saat dewasa. Sori berbentuk garis tipis berada disepanjang kanan kiri tulang anak daun. Spesimen: RangBSNS1, RangBSNS2 Nery Sofiyanti, Rangsang 2017.

Blecnum sp. Terestrial. Daun majemuk, anak daun tersusun berseling. Anak daun hijau merah saat muda dan hijau terang saat dewasa. Sori berbentuk garis tipis berada disepanjang kanan kiri tulang anak daun, mulai dari pertengahan anak daun. Spesimen: RangBSPNS1, RangBBSPNS2 Nery Sofiyanti, Rangsang 2017.

Stenochlaena palustris (Burm. f.) Bedd. Terestrial. Daun majemuk, dimorfik. Daun steril berwarna merah kecoklatan saat muda, hijau saat tua. Anak daun mempunyai ujung runcing tepi bergeririgi. Daun fertil majemuk, anak daun membentuk garis Sori akrostikoid, menyelubungi permukaan bawah anak daun Spesimen: RangSPNS1, RangSPNS2 Nery Sofiyanti, Rangsang 2017.

\section{Davalliaceae.}

Davallia denticulata (Burm. f.) Mett. ex Kuhn. Epifit. Rhizom bersisik, menjalar. Daun majemuk, dimorfik. Bentuk daun menyerupai segitiga. Sori berada dileukan pinula, bentuk cawan. Spesimen: RangDTNS1, RangDTNS2 Nery Sofiyanti, Rangsang 2017

\section{Dennstaedtiac}

Pteridium caudatum L. (Maxon). Terestrial. Daun majemuk. Rhizom menjalar. Stipus keras, coklat kehijauan. Lamina membentuk segitiga, panjang bisa mencapai $1 \mathrm{~m}$ atau lebih, majemuk agnda Sori dipermukaan bawah pinula, bulat. Spesimen: RangPCNS1, RangPCNS2 Nery Sofiyanti, Rangsang 2017

\section{Nephrolepidaceae}

Nephrolepis hirsutula (G. Forst.) C. Presl. Terestrial atau epifit. Daun muda berambut putih, majemuk, lamina linier, panjang mencapai 1 meter atau lebih. Sori bulat berada di permukaan bawah anak daun. Indusium membualat. Spesimen: RangNHNS1, RangNHNS2 Nery Sofiyanti, Rangsang 2017

\section{Onocleaceae}

Matteuccia struthiopteris (L.) Tod. Terestrial. Rhizom pendek, agak tegak. Daun majemuk, hijau muda. Tepi anak daun berlekuk. Sori tersusun disepanjang elkukan tepi anak daun. Spesimen: RangMSNS1, RangMSNS2 Nery Sofiyanti, Rangsang 2017

\section{Polypodiaceae}

Drynaria sparsisora (Desv.) T. Moore. Epifit. Rhizom menjalar, bersisik coklat tua. Daun penyangga membulat, tepi berlekuk, berada pada bagian bawah daun fertil. Daun fertil hijau, kaku, tepi berlekuk dalam. Sori bulat kecil, coklat muda, tersebar di permukaan bawah. Spesimen: RangDSNS1, RangDSNS2 Nery Sofiyanti, Rangsang 2017

Pyrosia hetrophyla L.) M.G. Price. Epifit. Rhzome merambat, coklat tua kehitaman. Daun tunggal, dimorfik. Daun steril lanset, bagian tengah agak melebar, warna hijau terang, $1,3 \times 5 \mathrm{~cm}$, tepi agak bergelombang. Daun feril linier, $8-15 \mathrm{~cm} \mathrm{x} 1 \mathrm{~cm}$. sori membentuk garis disepanjang tepi daun. Spesimen: RangPHNS1, RangPHNS2 Nery Sofiyanti, Rangsang 2017

Pyrrosia piloselloides (L.) M.G. Price. Epifit. Rhzome merambat, coklat tua kehitaman. Daun tunggal, dimorfik. Daun steril membulat, 1 x $1.5 \mathrm{~cm}$, berdaging, tepi rata. Daun feril linier, $5-10 \mathrm{~cm} \times 1$ $\mathrm{cm}$. sori membentuk garis disepanjang tepi daun. Spesimen: RangPPNS1, RangPPNS2 Nery Sofiyanti, Rangsang 2017

Selliguea feei Bory. Terestrial. Rhizom menjalar, pendek. Daun tunggal, tangkai coklat kehitaman, berkilat. Lamina hijau gelap, tepi agak bergelombang. Sori berbentuk garis, berada di kanan kiri tulang daun, memenuhi permukaan bawah daun. RangSFNS1, RangSFNS2 Nery Sofiyanti, Rangsang 2017

\section{Pteridaceae}

Acrostichum aureum L. Habitat tepi pantai. Habitus semak, berkoloni, tinggi bisa mencapai $2.5 \mathrm{~m}$. Daun majemuk, anak daun bagian bawah steril dan bagian atas fertil,, saat muda berwarna merah kecoklatan. Anak daun steril $4-5 \times 25-35 \mathrm{~cm}$. Sori menutupi permukaan bawah daun fertil. Spesimen: RangAANS1, RangAANS2 Nery Sofiyanti, Rangsang 2017 
Acrostichum speciosum Willd. Habitat tepi pantai. Habitus semak, berkoloni, tinggi bisa mencapai $1 \mathrm{~m}$. Daun majemuk, anak daun bagian bawah steril dan bagian atas fertil, lancet. Anak daun steril saat muda berwarna merah kecoklatan, hijau saat dewasa, 3-4 $\mathrm{x}$ $20-30 \mathrm{~cm}$. Sori menutupi permukaan bawah daun fertil. Spesimen: RangASNS1, RangASNS2 Nery Sofiyanti, Rangsang 2017

Adiantum latifolium L. Terestrial, ternaungi. Daun majemuk dengan stipus keras coklat kehitaman, anak daun menyerupai jajaran genjang, hijau muda.. Spesimen: RangALNS1, RangALNS2 Nery Sofiyanti, Rangsang 2017

Adiantum peruvianum Tersetrial. Stous hitam, anak daun hicu cerah dan lebar. Sori pada tepi daun dengan indusium semu berbentuk ginjal. Klotzsch. Spesimen: RangAPNS1, RangAPNS2 Nery Sofiyanti, Rangsang 2017

Pteris vitata. Terestrial. Daun majemuk, anak daun berseling, dengan pangkal agak memeluk rachis. Sori berbentuk garis disepanjang tepi anak daun. Spesimen: RangPVNS1, RangPVNS2 Nery Sofiyanti, Rangsang 2017

Taenitis blechnoides (Willd.) Sw. Terestrial. Paku dimorfik. Daun steril majemuk, hijau tua, anak tersusun berseling. Daun fertil majemuk, anak daun berseling. Sori berbentuk garis, berada diantara tepi daun dan tulang daun. Spesimen: RangTBNS1, RangTBNS2 Nery Sofiyanti, Rangsang 2017

Ordo Gleicheniales dicirikan dengan adanya cabang yang menjalar dan bisa mencapai 10 meter dengan percabangan dikotom (Piggott 1996, Sofiyanti et al. 2015). Jenis Dicranopteris linearis merupakan jenis yang paling banyak dijumpai dengan daerah penyebaran yang luas. Ordo Lygodiales mempunyai satu famili saja yaitu Lygodiaeae dengan jumlah jenis sekitar 26 jenis (Zhang \& Hanks, 2013). Pada umumnya anggota famili ini mempunyai batang bercabang dan menjalar dengan ental panjang serta majemuk berselingan. Lygodiaceae juga mempunyai tipe daun dimorfik karena daun steril dan daun fertil yang berada pada stipus yang berbeda (Piggott 1996), seperti yang dijumpai pada jenis Lygodium microphyllum. Jenis ini merupakan salah satu jenis yang banyak ditemukan di tepi kebun atau hutan, merambat pada tumbuhan lain. Lygodium microphyllum mempunyai daun majemuk berselingan, dengan pinula kecil dan jarang.

Ordo Polypodiales mempunyai sporangia dengan anulus vertikal serta bertangkai dan stomium. Dewasa ini,
Polypodiales meliputi sekitar $80 \%$ jenis paku (Alan et al. 2006). Penelitian ini hanya dijumpai 9 famili (Tabel 1). Famili umlah jenis terbanyak (6 jenis) ditemukan pada famili Pteridaceae dan diikuti dengan famili Polypodiaceae dan Blecnaceae, masing masing 4 jenis. Famili Pteridaceae mempunyai jumlah jenis hampir 1000 jenis (Zhang et al. 2013), sedangkan Polypodiaceae mempunyai jumlah jenis lebih tinggi dibandingkan Pteridaceae, yaitu sekitar 1.200 jenis (Silva 2017; Tryon \& Tryon 1982). Gambar 2 menunjukan contoh jenis tumbuhan paku yang ditemukan di lokasi kajian.

\section{Hasil kajian palinologi}

Pembuatan preparat spora dilakukan pada 21 jenis tumbuhan paku yang ditemukan di Pulau Rangsang. Sedangkan 2 jenis paku (Blechnum sp. dan Adiantum latifolium) tidak dibuat preparat spora karena pada saat di lapangan tidak ditemukan individu yang mengasilkan spora. Tipe dasar spora tumbuhan paku yang ditemukan di Pulau Rangsang adalah monolet (14 jenis), dan trilet (7 jenis). Spora monolet (Gambar 2a-n) merupakan spora yang berbentuk ginjal dengan satu apertura monosulkat di bagian proximal. Gambar 2o-u menunjukan spora trilet dengan laesura trikotomosulkat. Sedangkan untuk mengetahui karakteristik spora jenis Blechnum sp. dan Adiantum latifolium, dilakukan penelusuran referensi mengenai kajian sporanya pada penelitian sebelumnya. Pada umumnya anggota Famili Blechnaceae, termasuk Blechnum mempunyai spora monolet (Nayar et al. 1966; Passareli et al. (2010);) sedangkan jenis Adiantum latifolium memiliki spora trilet (Vijayakhan et al. 2016; Wang et al.2017). Tabel 2 menyajikan karakteristik spora setiap jenis yang diamati.

Pada penelitian ini, tipe spora monolet dengan laesura monosulkat dijumpai pada tumbuhan paku dari famili Aspleniaceae, Athyriaceae Blechnaceae, Davalliaceae Dennstaedtiaceae Glecheniaceae, Lygodiaceae, Nephrolepidaceae dan Onocleaceaae. Hasil pada penelitian ini mendukung kajian oleh Lashin (2012), Lilian (2010), Sofiyanti et al. (2015; 2019) dan Vijayakhan et al. (2016) mengenai karakteristik spora monolet pada famili-famili tersebut. Spora trilet dengan laesura trikomonosulkat dijumpai pada anggota famili Glecheniaceae, Lygodiaceae dan Pteridaceae. Kajian spora dari jenis Glecheniaceae (Juhasz, 1977), Lygodiaceae (Misra \& Tiwari 2015; Haq 2017; Mazumbar 2018) dan Pteridaceae (Huang et al. 2011; Marpaung et al. 2016) juga menunjukan spora trilet. Pada jenis-jenis Pteridaceae spora yang dominan adalah trilet, namun beberapa jenis juga menunjukan spora monolet, seperti dilaporkan oleh Salimpour et al. (2011). 


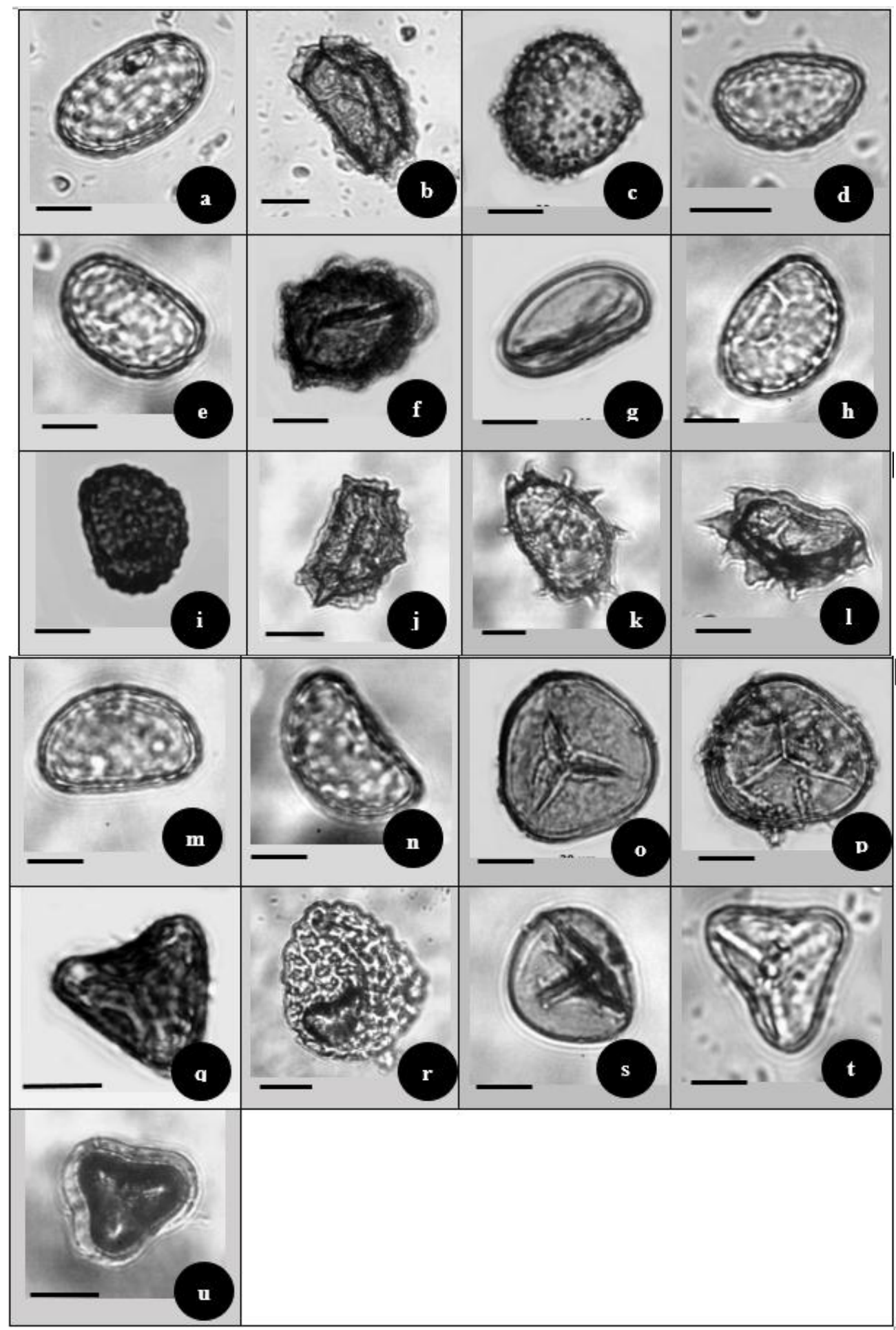

Gambar 1. Morfologi spora paku di Pulau Rangsang (a-n spora trilet, m-u spora trilet)., a. Asplenium longissimum, b. Asplenium nidus, c. Blechnum ocidentale, d. Blechnum serrulatum, e. Davallia denticulata, f. Diplazium esculentum, g. Drynaria sparsisora, h. Matteuccia struphtiopteris., i. Neprolepis hirsutula, j. Pteridium caudatum, k. Pyrrosia phylloseloides, 1. Pyrrosia heterophyla, m. Selligueae feei., n. Stenochlaena palustris, o. Acrostichum aureum, p. Acrostichum speciosum, q. Adiantum peruvianum, r. Lygodium microphyllum s. Pteris vitata, t. Dicranopteris linearis, u. Taenitis blechnoides, (skala $=20 \mu \mathrm{m})$. 
Tabel 3. Karakteristik spora tumbuhan paku di Pulau Rangsang

\begin{tabular}{|clcccc|}
\hline No. & \multicolumn{1}{c}{ Nama Jenis } & Tipe spora & Laesura & Ukuran $(\boldsymbol{\mu m})$ & Tipe ukuran \\
\hline 1 & Asplenium nidus & monolet & monosulkat & $60,90 \pm 4,28$ & Besar \\
\hline 2 & Asplenium longissimum & monolet & monosulkat & $44,80 \pm 4.50$ & Medium \\
\hline 3 & Blechnum occidentale & monolet & monosulkat & $45.10 \pm 4.50$ & Medium \\
\hline 4 & Blechnum serrulatum & monolet & monosulkat & $46,08 \pm 5,75$ & Medium \\
\hline 5 & Blechnum sp. & monolet* & monosulkat* & NA & NA \\
\hline 6 & Davallia denticulata & monolet & monosulkat & $35,23 \pm 5,75$ & Medium \\
\hline 7 & Diplazium esculentum & monolet & monosulkat & $66,23 \pm 3.00$ & Besar \\
\hline 8 & Drynaria sparsisora & monolet & monosulkat & $39.05 \pm 5,10$ & Medium \\
\hline 9 & Matteuccia struthiopteris & monolet & monosulkat & $40.50 \pm 3.05$ & Medium \\
\hline 10 & Nephrolepis hirsutula & monolet & monosulkat & $38,23 \pm 3.00$ & Medium \\
\hline 11 & Pteridium caudattum & monolet & monosulkat & $21,05 \pm 5,50$ & Medium \\
\hline 12 & Pyrrosia heterophyla & monolet & monosulkat & $76.09 \pm 6.70$ & Besar \\
\hline 13 & Pyrrosia piloselloides & monolet & monosulkat & $84,65 \pm 9,10$ & Besar \\
\hline 14 & Selliguea feei Bory & monolet & monosulkat & $48,30 \pm 2.50$ & Medium \\
\hline 15 & Stenochlaena palustris & monolet & monosulkat & $43,73 \pm 4,60$ & Medium \\
\hline 16 & Acrostichum aureum & Trilet & trikotomosulkat & $59.00 \pm 6.20$ & Besar \\
\hline 17 & Acrostichum speciosum & Trilet & trikotomosulkat & $58.08 \pm 2.08$ & Besar \\
\hline 18 & Adiantum latifolium & Trilet** & Trikotomosulkat** & $\pm 40 * *$ & Medium** \\
\hline 19 & Adiantum peruvianum & Trilet & trikotomosulkat & $55.08 \pm 2.00$ & Besar \\
\hline 20 & Dicranopteris linearis & Trilet & trikotomosulkat & $39,44 \pm 5,23$ & Medium \\
\hline 21 & Lygodium microphyllum & Trilet & trikotomosulkat & $59,50 \pm 7,20$ & Besar \\
\hline 22 & Pteris vitata & Trilet & trikotomosulkat & $47,12 \pm 4,79$ & Medium \\
\hline 23 & Taenitis blechnoides & trikotomosulkat & $42.00 \pm 5.65$ & Medium \\
\hline
\end{tabular}

Keterangan: sumber * Nayar et al. 1966 dan Passarelli et al. (2010); ** Vijayakhan et al. (2016) dan Wang et al. (2017)

Tipe spora berdasarkan laesura merupakan karakter yang konstan untuk setiap jenis tumbuhan paku, sehingga karakter ini sangat penting dalam kajian taksonomi. Karakteristik spora juga dapat dilihat dari ukurannya. Oleh karena itu pada penelitian ini, spora juga digolongkan berdasarkan ukuran aksis terpanjang. Ertmant (1972) membagi spora menjadi 6 berdasarkan ukuran, namun pada penelitian ini hanya 2 tipe spora saja yang ditemukan yaitu spora medium $(25-50 \mu \mathrm{m})$ dan spora besar $(50-100 \mu \mathrm{m})$. Spora medium ditemukan pada 14 jenis paku dan spora besar sebanyak 7 jenis.

\section{Kesimpulan}

Sebanyak 23 jenis tumbuhan paku dari 9 Famili dan 3 ordo telah diidentifikasi dari Pulau Rangsang, Kepulauan Meranti, Provinsi Riau. Ordo Polypodiales merupakan ordo dengan jumlah jenis paling tinggi (21 jenis). Tipe spora yang ditemukan adalah monolet dan trilet dengan 2 tipe ukuran spora yaitu spora medium dan spora besar. Hasil yang diperoleh dalam penelitian ini memberikan data dasar jenis-jenis paku di Pulau Rangsang, Kepulauan Meranti, Riau serta karakteristik sporanya.

\section{Ucapan terima kasih}

Penulis mengucapkan terima kasih kepada KEMENRISTEK DIKTI yang telah mendanai penelitian ini melalui hibah Penelitian Dasar atas nama penulis pertama.

\section{Kontribusi Penulis}

Penulis pertama: Ide penelitian, koordinator lapangan, menyusun kerangka kerja, menyiapkan data di lapangan dan di laboratorium, menyusun drfat artikel. Penulis kedua: membantu pekerjaan di laboratorium bagian moroflogi spora, penulis ketiga dan keempat membantu pekerjaan di lapangan dan karakterisasi morfologi.

\section{Daftar Pustaka}

Alan R, Smith AR, Pryer KM, Schuettpelz E, Korall P, Schneider H \& Paul G. (2006). A classification for extant ferns. Taxon 55 (3): 705-731. doi:10.2307/25065646. JSTOR 25065646.

Christenhusz MJM, Zhang XC \& Schneider H. (2011). A linear sequence of extant families and genera of 
lycophytes and ferns. Phytotaxa 19: 5-22. DOI: http://dx.doi.org/10.11646/phytotaxa.19.1.2 https://www.biotaxa.org/Phytotaxa/article/view/p hytotaxa.19.1.2/18248

Erdtman G. (1972). Pollen Morphology and Plant Taxonomy. New York: Hafner Pub. Com.

Hakim AR. Sutikno S \& Fauzi M. (2016). Analisis Laju Abrasi Pantai Pulau Rangsang di Kabupaten Kepulauan Meranti dengan Menggunakan Data Satelit. Jurnal Sains dan Teknologi 13(2). DOI: http://dx.doi.org/10.31258/jst.v13.n2.p\%25p. https://jst.ejournal.unri.ac.id/index.php/JST/articl e/view/3335/3253

Haq F. (2017). Morpho-Anatomical Description Of Lygodium Hazaricum Haq A New Contribution To The Fern Flora Of Pakistan. Tropical Plant Research, 4(2): 358-362. DOI: 10.22271/tpr.2017.v4.i2.047.

http://www.tropicalplantresearch.com/archives/20 17/vol4issue2/47.pdf

Huang Y, Hsu S, Hsieh T, Chou H \& Chiou H. (2011). Three Pteris species (Pteridaceae: Pteridophyta) reproduce by apogamy. Botanical Studies 52: 7987.

https://www.researchgate.net/publication/286056 813_Three_Pteris_species_Pteridaceae_Pteridoph yta_reproduce by apogamy

Jeffrey P. (2004). The Plant Tree Of Life: An Overview And Some Points Of View. American Journal of Botany 91 (10): 1440. doi:10.3732/ajb.91.10.1437. PMID 216523 02.

https://www.researchgate.net/publication/512008 76 The plant tree of life_An_overview and so me_points_of_view

Johansen AD. (1940). Plant Microtechnique. McGrawHill Book Company, Inc. London https://archive.org/details/in.ernet.dli.2015.27182 4/page/n13/mode/2up

Juhasz M. (1977). Gleicheniaceae Spores From Lower Cretaceous Deposits O F Hungary. Acta Biologica Szeged. 23 (1-4): 3-17. http://acta.bibl.uszeged.hu/id/eprint/21871

Lashin GAM. (2012). Palynological Studies of Some Species of Aspleniaceae-Pteridophyta. American Journal of Plant Sciences 3: 397-402 http://dx.doi.org/10.4236/ajps.2012.33048. https://www.scirp.org/html/132600277_17930.htm

Marpaung AA, Sofiyanti N. \& Iriani D. (2016). Morfologi spora paku Pteridaceae di Hutan PT. CPI Rumbai Riau. Jurnal Riau Biologia 1 (2): 149 - 154. https://jrb.ejournal.unri.ac.id/index.php/JRB/articl e/view/3775/3678

Mazumdar J. (2018). Based On Spore Morphology Lygodium Giganteum - Not A Synonym Of Lygodium Yunnanense (Lygodiaceae). International Journal Of Advance Research And Innovative Ideas In Education, 4 (3): 927-928. DOI: $\quad 16.0415 /$ IJARIIE-8523. http://ijariie.com/AdminUploadPdf/Based_on_Sp ore_morphology_Lygodium_giganteum_\%E2\%8 0\%94_not_a_synonym_of_Lygodium_yunnanens e__Lygodiaceae_ijariie8523.pdf

Misra PC \& Tiwari S. (2015). Pteridophytes Of Nepal: Family- Lygodiaceae. Indian Journal of Scienctific Research 6(2): 131-136. http://www.ijsr.in/upload/465474946Chapter_24. pdf

Kamau HN. (1992). Germplasm Exploration and Collection. Dinteria 23: 50-54. https://journals.co.za/docserver/fulltext/dinteria/1 992/23/65.pdf?expires $=1584261171 \&$ id=id\&accn ame=guest \&checksum=C6C62853ECDCF30406 6F43D0A201D5A5

Nayar BK, Bajpai N. \& Raza F. (1966). Morphological studies on some species of Blechnum, Doodia, Woodwardia and Stenochls alimpouraena: I. The gametophytes and the juvenile sporophytes. Botanical Journal of the Linnean Society 59 (380): 405-423, https://doi.org/10.1111/j.10958339.1966.tb00071.x

Passarelli, Lilian M, Galán Y, Maria J, Prada, Carmen, Roller \& Cristina H. (2010). 'Spore morphology and ornamentation in the genus Blechnum (Blechnaceae). Grana : 1-10. http://dx.doi.org/10.1080/00173134.2010.524245

Piggott AG. (1996). Fern of Malaysia in Color. ropical Press Sdn.Bhd, Malaysia.

Salimpour F, Nazi M. \& Mazooji. (2011). Spore Morphology Of Pteridaceae In Iran 1 Australian Journal Of Basic And Applied Sciences, 5(10): 1154-1156. 
http://www.ajbasweb.com/old/ajbas/2011/Octobe r-2011/1154-1156.pdf

Silva, AG. \& Schwartsburd, PB. (2017). Ferns of Viçosa, Minas Gerais State, Brazil: Polypodiaceae (Polypodiales, Filicopsida, Tracheophyta). Hoehnea 44(2): 251-268. http://dx.doi.org/10.1590/2236-8906-95/2016

Smith AR. (1995). Polypodiaceae. In: P.E. Berry, B.K. Holst \& K. Yatskievych (eds.). Pteridophytes, Spermatophytes: Acanthaceae-Araceae. In: J.A. Steyermark, P.E. Berry \& B.K. Holst (gen. eds.). Flora of the Venezuelan Guayana. Missouri Botanical Garden Press, St. Louis 2: pp. 219-249.

Sofiyanti N. (2013). The diversity of epiphytic fern on the oil palm tree (Elaeis guineensis Jacq.) in Pekanbaru, Riau. Jurnal Biologi XVII (2). https://ojs.unud.ac.id/index.php/BIO/article/view/ $12068 / 8380$

Sofiyanti N., Iriani D., Fitmawati \& Roza AA. (2015). Stenochlaena Riauensis (Blechnaceae), A New Fern Species From Riau, Indonesia. Bangladesh J. Plant Taxon. 22(2): 137-141. DOI: https://doi.org/10.3329/bjpt.v22i2.26075 https://www.banglajol.info/index.php/BJPT/articl e/view/26075

Sofiyanti, N. (2019). Aspleniaceae and Polypodiaceae from the coastal regions of Riau, Indonesia and their palynological study. Tropical Plant Research. 6(2): 326-334, 2019 DOI: 10.22271/tpr.2019.v6.i2.042.

http://www.tropicalplantresearch.com/archives/20 19/vol6issue2/42.pdf

Sofiyanti. N., Isda MN, Juliantari, E.Suriatno R. \& Pranata S. (2019). The inventory and spore morphology of ferns from Bengkalis Island, Riau Province, Indonesia. Biodiversitas 20(11): 3223$3236 \quad$ DOI: $\quad 10.13057 /$ biodiv/d201115. https://smujo.id/biodiv/article/view/4416/3486

Tryon RM \& Stolze RG. (1993). Pteridophyta of Peru, part V: 18. Aspleniaceae - 21. Polypodiaceae. Fieldiana, Botany, new series 32: 1-190. Tryon, R.M. \& Tryon, A.F. 1982. Ferns and allied plants, with special reference to Tropical America. Springer - Verlag, New York. https://doi.org/10.5962/bhl.title.2547.

https://www.biodiversitylibrary.org/bibliography/ 2547\#/summary
Vijayakanth P \& Sathish S. (2016). Studies on the spore morphology of pteridophytes from Kolli Hills, Eastern Ghats, Tamil Nadu, India. International Journal of Research in Engineering and Bioscienc 4:1-12. http://www.ijreb.org/manuscript/IJREB_5826ffc2 4675d.pdf

Wang AH, Wang FG, Zhang WW, Ma XD, Li XW \& Li QF. (2017). Revision of series Gravesiana (Adiantum L.) based on morphological characteristics, spores and phylogenetic analyses. PLoS ONE 12(4): e0172729. https://doi.org/ 10.1371/journal.pone.0172729 https://journals.plos.org/plosone/article?id=10.13 71/journal.pone.0172729

Wulandari D., Sofiyanti N. \& Fitmawati. (2016). Keanekaragaman Jenis Polypodiaceae Di Hutan PT. CPI Rumbai Provinsi Riau Berdasarkan Karakter Morfologi. Jurnal Riau Biologia, 1 (2): 135 - 139. https://fmipa.unri.ac.id/wpcontent/uploads/2018/10/Jenis-Jenis-

Polypodiaceae-di-Hutan-PT.-CPI-Rumbai-

Provinsi-Riau-Berdasarkan-KarakterMorfologi.pdf

Yusna M, Sofiyanti N. \& Fitmawati. (2016). Keanekaragaman Pteridaceae Berdasarkan Karakter Morfologi dan Fitokimia di Hutan PT. Chevron Pacific Indonesia (PT. CPI) Rumbai. Jurnal Riau Biologia, 1 (2): 165 - 172. https://fmipa.unri.ac.id/wpcontent/uploads/2018/10/KeanekaragamanPteridaceae-Berdasarkan-Karakter-Morfologidan-Fitokimia-di-Hutan-PT.-Chevron-Pacific$\underline{\text { Indonesia.pdf }}$

Zhang XC \& Hanks JG. (2013). Lygodiaceae. Pp. 118121 in Z. Y. Wu, P. H. Raven \& D. Y. Hong, eds., Flora of China Vol. 2-3 (Pteridophytes). Beijing: Science Press; St. Louis: Missouri Botanical Garden Press. http://flora.huh.harvard.edu/china/mss/volume02/ Flora_of_China_Volume_2_3_Lygodiaceae.pdf

Zhang GM, Liao WB, Ding MY, Lin YX, Wu ZH, Zhang CH, Dong SY, Prado MG, Gilbert G. Yatskievych. Ranker TA. Hooper EA. Alverson ER. Metzgar ZR. Funston AM. Masuyama S... M. Kato. (2013). Pteridaceae. (in Z. Y. Wu, P. H. Raven \& D. Y. Hong, eds., Flora of China, Vol. 2-3 Pteridophytes) Beijing: Science Press; St. Louis: Missouri Botanical Garden Press. Pp. 169-256. http://efloras.org/florataxon.aspx?flora $\mathrm{id}=2 \& \operatorname{tax}$ on id=51 